\title{
POR UM PERCURSO EPISTEMOLÓGICO DA NOÇÃO DE SUJEITO NA LINGUÍSTICA
}

\author{
AN EPISTEMOLOGICAL OVERVIEW OF THE SUBJECT NOTION IN LINGUISTICS THEORETICAL FIELD \\ POR UNA RUTA EPISTEMOLÓGICA DE LA NOCIÓN DE SUJETO EN LA LINGÜÍSTICA
}

\author{
Ismael Ferreira-Rosa* \\ Universidade Federal de Uberlândia - UFU, Uberlândia, BR
}

\begin{abstract}
RESUMO: O presente artigo tem por fito delinear um breve percurso epistemológico da noção de sujeito no campo teórico da ciência humana sobre a língua(gem). Atentando aos movimentos epistemológicos aventados por Domingues (1999) nas humanidades, alvitra-se uma reflexão sobre o lugar do sujeito na esteira teórico-conceptual da Linguística Moderna, desde sua fundação enquanto ciência, por Ferdinand de Saussure, passando pelas vertentes gerativista, funcionalista e enunciativa, até chegar à teoria do discurso proposta por Michel Pêcheux, esteira teórica cujos fundamentos sobre a noção de sujeito são os pontos precípuos desta reflexão. Procura-se, mediante um breve panorama e um cotejo discursivo, evidenciar os movimentos de delir/substanciar, unificar/dispersar o sujeito frente ao mundo da linguagem, mostrando os deslocamentos teóricos que a Análise do Discurso de linha francesa promoveu na conjunção epistemológica de sua constituição, enquanto uma teoria do discurso, centrada nos vértices do Marxismo, da Linguística e da Psicanálise.
\end{abstract}

PALAVRAS-CHAVE: sujeito; epistemologia; linguagem; Linguística.

\begin{abstract}
This paper aims at delineating a brief epistemological overview of the notion of subject in the theoretical science of language. Paying attention to epistemological movements proposed by Domingues (1999) in the humanities, it is proposed a discussion about the place of subject in the theoretical and conceptual Modern Linguistics field, from its foundation as a science, by Ferdinand de Saussure, passing through the generative theory, functionalist and enunciative proposes, until reaching the discourse theory proposed by Pêcheux, a theoretical space whose foundations about the notion of subject are the main point of discussion. The objective here is, through a brief overview and a discursive collation, to highlight the movements of rubbing out/pointing out, unifying/dispersing the subject in the language world, showing the theoretical displacements that French Discourse Analysis promoted throughthe epistemological conjunction of its constitution as a discourse theory, centered on the vertices of Marxism, Linguistics and Psycho analysis.

KEYWORDS: subject; epistemology; language; Linguistics.
\end{abstract}

RESUMEN: El presente artículo tiene por objetivo delinear una breve ruta epistemológica de la noción de sujeto en el campo teórico de la ciencia humana sobre el lengua(je). Poniendo atención a los movimientos epistemológicos aventados por Domingues (1999) en las humanidades, se propone una reflexión sobre el lugar del sujeto en el espacio teórico-conceptual da Lingüística Moderna, desde su fundación como ciencia, por Ferdinand de Saussure, pasando por las vertientes generativista, funcionalista y enunciativa, hasta que se llega a la teoría del discurso propuesta por Michel Pêcheux, espacio teórico cuyos fundamentos sobre la noción de sujeto son los puntos capitales de esta reflexión. Se procura, mediante un breve panorama y un cotejo discursivo, evidenciar los movimientos de delir/substanciar, unificar/dispersar el sujeto frente al mundo del lenguaje, mostrando los movimientos teóricos que el Análisis del Discurso de línea francesa promocionó en la conjunción epistemológica de su constitución, como una teoría del discurso, centrada en los vértices del Marxismo, de la Lingüstica y del Psicanálisis.

PALABRAS-CLAVE: sujeto; epistemologia; linguaje; Lingüística.

\section{NOTA INTRODUTÓRIA}

Abordar a questão do sujeito em um campo de saber é, indubitavelmente, uma empreitada audaciosa, marcada por embates e contradições, os quais são polemizados pela complexidade e implexidade tentaculares das próprias vias de constituição do que se entende por sujeito. Uma noção assaz amplífica, obliquamente evidente e não evidente, cujos tentáculos teórico-conceptuais tangem as superfícies conceptuais da Filosofia, da Religião, da Antropologia, da Psicologia, da História e da Linguística, para citar algumas.

Desde uma subjetividade resignada a uma divindade absoluta, central e suprema, a uma subjetividade fluida e líquida, dissolvida pelos escoamentos socioculturais da modernidade ou pós-modernidade instável, como

\footnotetext{
* Doutorando e bolsista CAPES no Programa de Pós-Graduação em Estudos Linguísticos da Universidade Federal de Uberlândia (UFU). Mestre em Linguística e Linguística Aplicada pela UFU e pesquisador em Análise do Discurso de linha francesa vinculado ao Laboratório de Estudos Polifônicos (LEP) da UFU e ao Grupo de Estudos e Pesquisas em História do Português (GEPHPOR) da Universidade Federal de Goiás Câmpus Catalão. E-mail: ismfero@gmail.com.
} 
alguns denominam, a concepção de sujeito - indivíduo, ser ou homem, cada acepção marcada pelas especificidades conceptuais do lugar teórico de cujo ínterim procedem - é balizada por (des)locamentos e (des)construções, advindos das formas de se entender o homem frente ao mundo, seja real, ideal ou imaginário, e frente às relações que esse homem estabelece com o mesmo mundo e seus objetos.

Nesse percurso, intrinsecamente vinculado às condições sócio-históricas e ideológicas das diferentes épocas, das formas de entendimento do que é sujeito, que remontam ao mito das sociedades primitivas, passando pela Filosofia na Antiguidade Clássica e pela Teologia na Idade Média, até afluir na Ciência da Modernidade, a posição da Epistemologia, alvitrada por Domingues (1999), observa quatro principais baluartes conceptuais que suportam a construção do pensamento sobre o sujeito nas ciências humanas: o cosmológico, o teológico, o mecânico e o histórico.

No mundo cosmológico da Antiguidade Clássica, o homem “[...] é pensado a partir do cosmos [...], vale dizer, de uma alma cósmica universal na qual o espírito busca aquele princípio de vida e de movimento que confere às coisas humanas a necessidade de uma physis" (DOMINGUES, 1999, p. 15). O sujeito é compreendido nos crivos de uma interioridade intrínseca ao ser, no encalce de sua alma para o conhecimento de si, mediante práticas elucubrativo-especulativas. Isso revela a essência do axioma filosófico do pensamento socrático: "o homem é um ser em busca constante de si mesmo".

No segundo baluarte, o teológico, derivado da Idade Média, “[...] o homem é pensado a partir dos desígnios da providência divina e no seio dos 'mistérios' da doutrina da criação" (DOMINGUES, 1999, p. 16). Nessa concepção, o sujeito é o ser do pecado, imperfeito, que não se conhece à luz da razão e sob as categorias lógicas do pensamento que desvelam os segredos da alma, da interioridade imanente do homem. Ora, conhecer-se a si mesmo é, não mais por práticas especulativas e sim valorativo-identificatórias, ver-se “[...] como um ser que em sua autonomia [não] se basta a si mesmo, mas estando à mercê do bom Deus e a depender da sua graça" (DOMINGUES, 1999, p. 27). Portanto, do conhecimento de si, desloca-se para o imperativo da salvação de si, instaurando uma concepção do sujeito assujeitado, imperfeito, submisso aos dogmas e preceitos religiosos, que têm por escopo, como a própria denominação religião (do latim re-ligare) aponta, religar os homens a Deus, salvar o ser da perdição.

Já no mundo mecânico, construído na Modernidade, “[...] o homem adquire autonomia e é interrogado a partir dele mesmo e das condições da subjetividade, em busca dos 'dispositivos mecânicos' [...] postos no fundo do seu ser, os quais regulam suas relações de si consigo mesmo, com o outro e com o mundo" (DOMINGUES, 1999, p. 16). O sujeito, nessa esteira conceptual, passa do espaço das coisas para o espaço dos homens, dominando e determinando o curso do mundo e seus objetos. Mediante a construção de mecanismos - ferramentas tecnológicas e aportes científicos -, o homem prescinde dos cuidados de uma divindade maior e passa a cuidar-se de si mesmo por positividades.

Nesse mundo mecânico, Domingues (1999) fala de um homem-máquina que se dissipa da interioridade e do pecado pelas práticas empíricas de observação e análise lógica. Prima-se por uma invariabilidade e uma estaticidade positiva, em que o ser e as coisas são explicados por estruturas sólidas e palpáveis, marcadas por invariações e estabilidades. Essa visão confere ao sujeito e à sociedade uma fixidez e abandona "[...] ao devir um sem-número de fatos e acontecimentos, tidos como sem explicação ou simplesmente atribuindo-a ao acaso" (DOMINGUES, 1999, p. 39). A relação sujeito-eu-outro-mundo é mecânica, estrutural e se encontra pelo imo da natureza, explicada objetivamente por métodos científicos. Leis e dados naturais são fatores motrizes de entendimento do homem, do mundo e de suas relações.

Contudo, esse centramento da natureza no homem - já que o inverso era um óbice, tendo em vista que não se podia situar o homem na natureza, afinal esse homem possuía uma interioridade que afirmava o seu ser (a alma), conforme expende Domingues (1999) - e a procura pelos mecanismos que regulam a relação natureza-sujeito eram um tanto quanto limitadores. Era preciso incorporar a essa relação o tempo "[...] e ainda o universo do devir, sob pena de perder aquilo que dá ao homem seu éthos e seu télos: a história." (DOMINGUES, 1999, p. 39).

É justamente nessa observação, emanada da passagem da Modernidade para essa nossa contemporaneidade, que centra o quarto baluarte teórico de concepção das formas de se entender o sujeito: o histórico. Nesse mundo da história, "[...] temos o descentramento do homem e a dissolução da natureza humana nas positividades da história e da cultura [...], buscando as razões de seus diferentes modos de ser na história ela mesma." (DOMINGUES, 1999, p. 16). O sujeito, por meio de práticas heurístico-hermenêuticas do 
devir, desconjunta-se do positivismo mecanicista que o maquinificara e se assenta na concepção “[...] do homem como ser de carência e de desejo, do homem como ser de artifício e de invenção, do homem como ser lacunar com o ego barrado e alma decaída no tempo, e buscando nas potências do tempo [...] o princípio interior do ser e lei do seu devir" (DOMINGUES, 1999, p. 42).

Nesse sentido, a partir da teoria marxista e da teoria freudiana, o homem é um ser descentrado. Descentrado de sua interioridade e da natureza positivo-estrutural do mundo pela história e pelo inconsciente. Por isso,

[...] o homem não controla e não é senhor sequer de sua subjetividade, com seu "si mesmo" barrado à consciência. E menos ainda de sua história, residindo seu segredo não na subjetividade [...], mas alhures, numa estrutura sem sujeito e sem fim absolutos: o modo de produção. (DOMINGUES, 1999, p. 44).

É nos modos de produção de sua própria dinâmica de se tornar, constituir-se sujeito frente a uma exterioridade, além dos domínios interiores de sua subjetividade e da mecanicidade da natureza vinculada ao ser, que o entendimento do que seja homem histórico deveria, então, centrar- se.

Mas será essa a concepção de sujeito que baliza o edifício teórico da Linguística, enquanto uma ciência humana que se ocupa dos fatos de linguagem? Será o sujeito entendido nos modos de produção de si consigo mesmo, de si com o outro, de si com o mundo pelo viés da linguagem, em uma relação eu-outrolinguagem-mundo? Qual a noção de sujeito que perdura no campo teórico-conceptual da Linguística?

Esses serão os questionamentos que nortearão a discussão que ora propomos neste trabalho. Alvitramos uma reflexão sobre o lugar do sujeito na esteira teórico-conceptual da Linguística Moderna, desde sua fundação enquanto ciência, por Ferdinand de Saussure, passando pelas vertentes gerativista, funcionalista e enunciativa, até chegar à teoria do discurso proposta por Michel Pêcheux, esteira teórica cujos fundamentos sobre a noção de sujeito serão os pontos precípuos de nossa discussão.

Procuraremos, mediante um breve panorama e um cotejo discursivo, evidenciar os movimentos de delir/substanciar, unificar/dispersar o sujeito frente ao mundo da linguagem, mostrando os deslocamentos teóricos que a Análise do Discurso de linha francesa (AD) promoveu na conjunção epistemológica de sua constituição enquanto uma teoria do discurso: Marxismo, Linguística e Psicanálise.

Para tanto, primeiramente delinearemos um breve percurso da noção de sujeito em quatro grandes e importantes estirpes teóricas da Linguística - Estruturalismo, Gerativismo, Funcionalismo e Teoria da Enunciação ${ }^{1}$. Posteriormente, abordaremos a teoria do discurso pecheutiana e os deslocamentos que instaura ao conjugar língua-sujeito-ideologia-inconsciente afluídos na questão do discurso, o objeto teórico nodal dessa teoria materialista das discursividades produzidas nas práticas linguageiras por, para e entre sujeitos.

\section{O SUJEITO NAS VIAS ESTRUTURAIS-ENUNCIATIVAS DA LINGUÍSTICA}

Ferdinand de Saussure, enquanto o precursor da Linguística, foi quem legou aos estudiosos que se ocupam dos fatos de linguagem inúmeras contribuições, cujos fundamentos, ainda em nossa coetaneidade, motivam acirradas discussões. Por meio do corte epistemológico que difere linguagem de língua e esta de fala, o autor definiu o objeto de estudo da Linguística, promovendo-a ao status de ciência. Se a linguagem "[...] é multiforme e heteróclita; a cavaleiro de diferentes domínios, ao mesmo tempo física, fisiológica e psíquica, ela pertence além disso ao domínio individual e ao domínio social” (SAUSSURE, 2006, p. 17), e, portanto, não passível de classificação em nenhuma categoria de fatos humanos e de atribuição de uma unidade, não deve ser o objeto de estudo da Linguística.

\footnotetext{
Poderíamos eleger, para esse cotejo discursivo, outras vertentes teóricas da Linguística dentre tantas existentes, mas optamos por esse recorte em específico considerando que essas quatro estirpes teóricas são muito debatidas, recorrentes e importantes no cenário epistemológico dos estudos da linguagem. Além do mais, dada a extensão e a natureza gênero-textual de um artigo teórico, não poderíamos abarcar um número maior de vertentes sem correr o risco de sermos extremamente superficiais e inconsistentes em nossas considerações.
} 
Para ser esse objeto, é imprescindível a homogeneidade, a unidade, a naturalidade lógica, enfim, uma estrutura estável e palpável, quesito positivo para o posto de ciências entre demais campos de saber.

Destarte, é a língua, também em detrimento da fala², que deve ocupar o lugar de objeto de estudo, pois é sistêmica, "[ [...] é um todo por si e um princípio de classificação" (SAUSSURE, 2006, p. 17). Ainda:

É um objeto bem definido no conjunto heteróclito dos fatos da linguagem. Pode-se localizá-la na porção determinada do circuito em que uma imagem auditiva vem associar-se a um conceito [...]; [e] é um objeto que se pode estudar separadamente [...]. A língua assim delimitada é de natureza homogênea: constitui-se num sistema de signos onde, de essencial, só existe a união do sentido e da imagem acústica [...], [e] é um objeto de natureza concreta, o que oferece grande vantagem para o seu estudo. (SAUSSURE, 2006, p. 22-23).

De tal modo, Saussure promove o corte, relegando, pelos claros motivos positivistas de se instaurar uma ciência (por conseguinte, um ato metodológico e de escolha teórica que não extirpa o mérito de seu posicionamento conceptual), o sujeito e a produção de sentidos na linguagem, dos estudos linguísticos.

O sujeito, na verdade concebido na esteira teórica do fundador da Linguística como indivíduo, não passa de um usuário desse sistema abstrato de signos regido por regras próprias para o estabelecimento de comunicação com outros indivíduos, servindo esse sistema como mediador entre pensamento e som, um construtor de unidades para as massas amorfas e nebulosas do pensamento (cf. SAUSSURE, 2006, p. 131).

Consequentemente, a língua “[...] é a parte social da linguagem, exterior ao indivíduo, que, por si só, não pode nem criá-la nem modificá-la; ela não existe senão em virtude de uma espécie de contrato estabelecido entre os membros da comunidade" (SAUSSURE, 2006, p. 22).

Com efeito, esse objeto da Linguística é uma realidade, uma natureza que só pode ser apreendida no homem, desvelando uma concepção mecanicista, aos moldes concepcionais do que vimos anteriormente no encetamento de nossa discussão, tal como se observa nesta passagem:

Se pudéssemos abarcar a totalidade das imagens verbais armazenadas em todos os indivíduos, atingiríamos o liame social que constitui a língua. Trata-se de um tesouro depositado pela prática da fala em todos os indivíduos pertencentes à mesma comunidade, um sistema gramatical que existe virtualmente em cada cérebro ou, mais exatamente, nos cérebros dum conjunto de indivíduos, pois a língua não está completa em nenhum, e só na massa ela existe de modo completo (SAUSSURE, 2006, p. 21).

Sendo assim, Saussure, ao definir e delimitar o objeto de estudo em uma visão linguística, assoma a língua à unidade da linguagem, hermetificando-a no âmbito da abstração e da homogeneidade, sem considerar a exterioridades.

Posteriormente, com o advento da teoria gerativa de Chomsky, ainda que inscrita em uma visão imanentista de língua ${ }^{4}$ concebida nos crivos de uma noção internalista-biológica, como órgão biológico da linguagem, uma faculdade inata ao homem, o sujeito não mais se submete a um sistema abstrato, estável e regido por regras incontornáveis.

Na verdade, o sujeito é um falante ideal, alguém que tem a capacidade inata para a linguagem, e, portanto, dotado de capacidades e competências para o desempenho linguístico. "Cada falante pode produzir e

\footnotetext{
${ }^{2} \mathrm{O}$ linguista genebrino propõe o par langue (língua) - parole (fala) também como uma forma de apuração do objeto da Linguística, relevando uma oposição dicotômica entre elas, em que a língua é sistêmica, objetiva e social; ao passo que a fala é variável, acidental, acessória e individual, imanente a cada falante, e, portanto, não deve, assim como a linguagem, assumir o posto de objeto de estudo de natureza linguística.

${ }^{3} \mathrm{O}$ precursor da ciência linguística assevera que "[...] a Lingüistica tem por único e verdadeiro objeto a língua, considerada em si mesma e por si mesma" (SAUSSURE, 2006, p. 271, grifos do autor). Dessa forma, a língua aponta para os fatores internos que demarcam uma posição epistemológica em relação aos estudos linguísticos estruturalistas. É definindo esse objeto que Saussure ressalta ainda os elementos exteriores como a etnologia, a relação entre a língua e a história política, a língua e a história das instituições e os fatos geográficos como fatores que não dizem respeito ao organismo interior do sistema. Para ele, é necessário que “[...] eliminemos dela [da língua] tudo que lhe seja estranho ao organismo, ao seu sistema” (SAUSSURE, 2006, p. 29).

${ }^{4}$ Chomsky (2006, p. 01) considera a língua/linguagem (não fazendo distinção entre elas) como "[...] o objeto natural, um componente da mente humana, representado fisicamente no cérebro e integrado ao patrimônio biológico da espécie”.
} 
entender um número indefinido de expressões lingüísticas no uso normal da linguagem.” (CHOMSKY, 2006, p. 02), sendo, desse modo, portador de uma capacidade extraordinária de criatividade de usar a linguagem, criando infinitas sentenças, mesmo sem nunca as ter ouvido.

O sujeito, na perspectiva chomskyana concebido como falante - aquele ser ideal que desempenha o sistema linguístico criativamente, dotado e predisposto geneticamente para a faculdade da linguagem -, tem domínio sobre o sistema, pois " $[\ldots .$.$] quando falamos, escolhemos livremente uma estrutura gerada por nosso$ procedimento recursivo e que está em harmonia com nossas intenções comunicativas” (CHOMSKY, 2006, p. 04).

Não obstante ter considerado o sujeito e sua competência da aquisição de um procedimento gerativorecursivo, o Gerativismo, no imo de uma ótica internalista, genético-biológica e cognitiva, também deliu a exterioridade e a heterogeneidade. Centrando-se em sua formalidade crítica, a gramática gerativa mostrou “[...] que a regularidade e a ausência de limites da sintaxe da língua natural podiam ser expressas por modelos gramaticais precisos dotados de processo recursivos" (CHOMSKY, 2006, p. 04), como também que “[...] as linguagens humanas são muito mais uniformes do que se pensava anteriormente" (p. 20).

Dessa forma, pelas vias de um ser ideal e da homogeneidade da linguagem enquanto um construto mental, Chomsky também insere seus estudos teórico-conceptuais em uma esteira mecânica da produção de conhecimentos, tendo em vista a positividade da invariabilidade e a unidade do sujeito e dos fatos de linguagem.

Nas práticas analíticas do Funcionalismo, cujo encetamento teórico precipuamente recai sobre a figura de Halliday, acresce-se um adendo: a interação social. Nessa vertente teórica da Linguística, assenta-se “[...] que as relações entre as unidades e as funções das unidades têm prioridade sobre seus limites e sua posição, e que entende a gramática como acessível às pressões do uso" (NEVES, 2004, p. 15).

A língua é concebida "[...] como um instrumento de interação social entre seres humanos, usado com o objetivo principal de estabelecer relações comunicativas entre os usuários" (NEVES, 2004, p. 19). E, por extensão, o sujeito é entendido como um usuário linguístico, que manipula a língua de acordo com intenções próprias para se interagir no social.

Assim, o indivíduo, porque portador de uma individualidade e intencionalidade, constitui-se um senhor de seu dizer que domina o sistema, o qual, por sua vez, torna-se sensível às pressões de uso e, portanto, dinâmico e instável às realizações da interação social, estabelecendo relações comunicativas.

E falamos de um indivíduo controlador de seu dizer porque, para o Funcionalismo,

[...] quando o falante diz algo a seu destinatário, sua intenção é provocar alguma modificação na informação pragmática dele. Para isso, o falante tem de formar alguma espécie de intenção comunicativa, uma espécie de plano mental concernente à modificação particular que ele quer provocar na informação pragmática do destinatário. (NEVES, 2004, p. 20).

Destarte, analisar fatos de língua em uma perspectiva funcional é descrever os fatos e os comportamentos linguísticos pelas vias do falante e do ouvinte, seus papéis e estatuto dentro da situação de interação, determinada socioculturalmente.

Todavia, mesmo com o adendo da interação social, ainda o foco permanece no nível descritivo-formal dos usos das formas linguísticas. Criam-se categorias, promovem-se descrições classificatórias, ou seja, instauram-se aportes técnico-científicos para a explicação da natureza estrutural da língua(gem), mediante realizações concretas das situações de uso comunicativo pelos falantes.

Logo, ainda a noção de sujeito permanece em um mundo mecanicista, pois descrições e análises funcionalistas têm por escopo fornecer "[...] um quadro explícito, sistemático e abrangente de sintaxe, semântica e pragmática unificadas como um todo." (GIVÓN, 1984, p. 40 apud NEVES, 2004, p. 24), e essa pragmática se volta às explanações formais dos usos da língua por falantes intencionais.

Conserva-se, desse modo, uma visão mecanicista do homem e da linguagem, pois quais os influxos do tempo e do devir nessas descrições sincrônicas dos usos linguísticos? Que sujeito individual e único é esse que, 
mediante a interação social com outros, torna a gramática da língua sensível aos usos? Esse sujeito não está em um lugar social? Não faz parte de uma história que reflete e refrata condições ideológicas? Como pode ser assim tão livre e consciente, provido de intenções inespaciais e atemporais? É da interioridade que provêm essas intenções?

Diante de respostas que não contemplam o devir histórico e o descentramento do homem, pois não constituem o foco de análise e escopo de investigação do Funcionalismo - por isso, não poderemos jamais extirpar os méritos de tal vertente teórica sem correr o risco de estabelecer uma crítica ilegítima, afinal não há como reclamarmos práticas teórico-analíticas de um campo de saber, as quais não constituem pontos nodais de estudo -, é-nos possível dizer, sem depreciações ou subestimações, que o sujeito na perspectiva funcional se situa em um mundo mecânico, cuja natureza linguística é descrita e explicada pelos usos de um falante intencional e dotado de razão e unicidade.

Com Benveniste, pertinentes inovações e abertura de outros horizontes foram instauradas nos estudos linguísticos. Ao propor uma teoria subjetiva da linguagem, o autor francês estabelece um lugar relevante ao sujeito, como aquele que se apropria da língua e a atualiza.

Sendo assim, desloca-se a questão do sentido, da significação da linguagem para o sujeito acionando essa linguagem. Se, no estruturalismo, o foco estava na estrutura; no gerativismo, na competência do falante; e no funcionalismo, a atenção estava voltada para o uso da língua pelo indivíduo; na teoria benvenistiana, o escopo se centra na enunciação, neste

[...] colocar em funcionamento a língua por um ato individual de utilização [...]. A relação do locutor com a língua determina os caracteres lingüísticos da enunciação. Deve-se considerá-la como o fato do locutor, que toma a língua por instrumento, e nos caracteres lingüísticos que marcam esta relação. (BENVENISTE, 1989, p. 82).

Em razão disso, o locutor - assim como o sujeito é entendido na esteira teórica de Benveniste: aquele que coloca a língua em funcionamento, constituindo o centro de produção de sentidos; o EGO, centro da enunciação - sobreleva-se aos fatos de linguagem, em que estes se configuram tão somente possibilidade da língua antes da enunciação, antes do ato individual de utilização dessa língua, que "introduz em primeiro lugar o locutor como parâmetro nas condições necessárias da enunciação” (BENVENISTE, 1989, p. 83).

Somente após a enunciação é que a língua se torna uma instância do discurso, aqui entendido como um ato único, produzido cada vez que se realiza um enunciado; ou seja, é o próprio ato de se produzir um enunciado e não o texto do enunciado (portanto, diferente de fala) que se torna objeto nodal da teoria enunciativa. Importa a manifestação da enunciação "[...] que emana de um locutor, forma sonora que atinge um ouvinte e que suscita uma outra enunciação de retorno" (BENVENISTE, 1989, p. 84).

Nesse sentido, a língua somente significa quando seu aparelho formal da enunciação (eu-tu-aqui-agora) é apropriado por um locutor que enuncia sua posição de locutor, implantando um outro perante si, em um dado espaço e um dado tempo.

Dito de outra forma, nas palavras do próprio autor da teoria enunciativa da linguagem,

[...] o ato individual de apropriação da língua introduz aquele que fala em sua fala. Este é um dado constitutivo da enunciação. A presença do locutor em sua enunciação faz com que cada instância de discurso constitua um centro de referência interno. Esta situação vai se manifestar por um jogo de formas específicas cuja função é de colocar o locutor em relação constante e necessária com sua enunciação. (BENVENISTE, 1989, p. 84).

Desse modo, o sujeito funciona como o centro, a fonte de produção de sentidos, revelando uma postura egocêntrica.

Indubitavelmente, foi um avanço da teoria enunciativa em trazer o sujeito de forma efetiva para os estudos linguísticos. Entretanto, essa concepção de locutor onipotente, uno, centrado e fonte do dizer, em torno do qual toda a significação é (des)construída, é bastante controvertida por vertentes teóricas que buscam analisar efeitos, ações e produção de sentidos dessa enunciação não somente pelo viés do locutor, mas por outros elementos da exterioridade. 
Se se centra precipuamente no sujeito, transformando-o num motriz em cujo entorno se dá a produção e funcionamento da língua, vislumbramos também a teoria enunciativa circunscrita a uma posição mecânica de construção de seus saberes. Entrevemos a hermetificação da produção de sentidos, vinculados a um ser onipotente e gerador das forças que constroem e/ou desconstroem os modos de significação dos fatos de linguagem, refugando influxos exteriores de outra ordem que não somente aqueles instaurados pela apropriação do aparelho formal da língua por um locutor, enquanto unidade gerativa de sentido.

Mas então existe alguma vertente teórica da Linguística que considera e inscreve seus saberes teóricoconceptuais sobre o sujeito no mundo histórico da produção de conhecimentos?

Cremos que a teoria do discurso preconizada por Michel Pêcheux assim o faz, cujos pressupostos discorremos doravante, cotejando com os saberes supra-apresentados.

\section{A ANÁLISE DO DISCURSO: IMBRICAMENTO TEÓRICO E O DESCENTRAMENTO DO SUJEITO}

A Análise do Discurso de linha francesa (AD), encetada por Michel Pêcheux (1938-1983) por meio do texto Analyse Automatique du Discours, publicado em 1969, é um campo de saber que se constitui no entremeio. Uma disciplina que não se resvala incisivamente no positivismo, já que, conforme aponta-nos Orlandi (1996, p. 23), "[…] não acumula conhecimentos meramente, pois discute seus pressupostos continuamente".

Destarte, é um lugar teórico em estado contínuo de movências e deslocamentos que alvitra uma concepção sócio-histórica e ideológica para a linguagem.

A $\mathrm{AD}$, nesse sentido, não se configura uma teoria pronta e acabada, mas um campo de interfaces na/da linguagem em constante (trans)formação e (des)construção. Enquanto uma disciplina de entremeio, reportase a espaços teóricos outros, estabelecidos de forma simultânea, mas marcada por relações contraditórias.

Esses espaços teóricos outros podem ser consubstanciados no tripé Linguística-Marxismo-Psicanálise que dá base teórico-conceptual para o quadro epistemológico da teoria do discurso.

A AD, então, nasceu da conjuntura dessas três tendências teóricas, nas quais há em comum o predomínio do exterior sobre o individual. Para a Linguística Estruturalista, construída a partir dos trabalhos de Saussure, os falantes submetem-se ao sistema linguístico; na Psicanálise de Lacan, o "eu" aparece descentrado e dividido, e o inconsciente aparece como determinante; e para o Marxismo, contrário à concepção cartesiana de que o sujeito é livre, dono de sua vontade, o sujeito é determinado/assujeitado pelas condições materiais e pela ideologia.

Portanto, no entremeio desses campos teóricos, instaura-se a conjunção materialismo histórico (enquanto teoria das formações sociais, suscetível às transformações que os elementos ideológicos podem produzir), linguagem (enquanto base material sobre a qual se desenrolam os processos discursivos) e discurso (enquanto processo de determinação histórico-ideológica da produção de sentidos), conjunção essa articulada a uma teoria da subjetividade, de natureza psicanalítica.

É no imbricamento ${ }^{5}$ das questões de língua, ideologia, inconsciente e história, que se instituiu o campo teórico da $\mathrm{AD}$, produzindo um lugar marcado pela relação contraditória existente entre essas regiões do conhecimento sobre as quais baseou seu quadro epistemológico. Um lugar transdisciplinar que, pensado a partir de espaços relacionais entre essas regiões do conhecimento, não se confunde ou se constitui enquanto teoria de aplicação de outras disciplinas. Antes, a Análise do Discurso é realizada a partir de deslocamentos dessas regiões teóricas, produzindo, assim, uma des-territorialização (cf. ORLANDI, 1996) e colocando em questão o sujeito do conhecimento e seu campo, seu objeto e seu método, face à teoria que produz.

\footnotetext{
Quando nos referimos a imbricamento, reportamo-nos ao pré-construído da discursividade produzida por esse elemento linguístico, apontando para o ato de dispor algo do qual parte aparece e parte é recoberta, de remontes de partes dispostas umas sobre as outras de forma interrelacionada aos moldes de uma interface. Uma discursividade, portanto, que descreve o efeito de remontes interfaciais que a teoria pecheutiana do discurso instaura.
} 
Desse modo, diferentemente de um sujeito livre e dominador de suas vontades de forma plena, uno, central e origem da produção de sentidos, um sujeito intencional, portador de extraordinárias capacidades de criação, o sujeito da AD é clivado, cindido, interpelado pelas condições de produção discursiva, dinâmico e heterogêneo, constituído na interação histórico-social.

A AD alvitra, de tal maneira,

[…] uma teoria não-subjetivista da subjetividade, que designa os processos de "imposição/dissimulação" que constituem o sujeito, "situando-o" (significando para ele o que ele ê) e, ao mesmo tempo, dissimulando para ele essa "situação" (esse assujeitamento) pela ilusão de autonomia constitutiva do sujeito, de modo que o sujeito "funcione por si mesmo.” (PECHEUX, 1997, p. 133, grifos do autor).

Encontramos, destarte, para a noção de sujeito, no interior da rede conceitual da AD francesa, um profícuo imbricamento teórico, por meio do qual se buscou na Linguística, no Marxismo e na Psicanálise subsídios conceptuais, dispostos e interrelacionados, em que partes das teorias foram retomadas. Falamos em partes porque Pêcheux não buscou os campos teóricos citados em sua completude, mas aspectos teóricoconceptuais para a instauração de uma outra forma de se conceber o sujeito, em que partes das teorias foram descobertas (retomadas e assumidas) e partes foram recobertas (deixadas de lado ou contestadas).

Para citar algumas descobertas e recobertas, porém longe de esgotar, podemos dizer que, da Linguística, recobriu-se a dicotomia saussureana de língua/fala, mediante a noção de discurso, mas descobriu-se a noção de sistema, incorporando-lhe a autonomia relativa; da Psicanálise, assume-se a noção de inconsciente, descentrando-se o sujeito, mas outras questões de ordem pragmática da manifestação ${ }^{6}$ são deixadas; e do Marxismo, retomou-se a noção de ideologia na releitura althusseriana, mas refutou-se a concepção de funcionalismo dos aparelhos ideológicos de Estado, deslocando-se para a noção de formações ideológicas.

Sendo assim, o que se observa é o imbricamento de talhes teórico-conceptuais dos quais partes foram retomadas e partes abjuradas, um imbricamento que possibilitou um outro olhar sobre o sujeito, sua constituição e concepção.

Esse sujeito, diferentemente do sujeito da concepção cartesiana, que o concebia como livre e senhor de sua vontade, é determinado e assujeitado, melhor dizendo, descentrado, pois, submetido ao sistema linguístico, é constituído pelo inconsciente e interpelado pela ideologia, obviamente apreendido no interior da história.

Porém, não se entenda os qualificadores determinado e assujeitado por um viés depreciativo e submissivo, mas instauradores de efeitos de um processo de constituição/ produção. Quando aludimos a determinado, reportamos-nos à questão de que o sujeito, para se instaurar como tal, passa por um processo de constituição, inscrevendo-se e circunscrevendo-se em lugares histórico-sociais e em lugares discursivos, do interior do quais enuncia e se posiciona discursivamente, sendo, portanto, determinado historicamente.

Quando nos referimos à questão do assujeitado, não se deve pensar no sentido althusseriano/marxista de sujeição do indivíduo à ideologia dominante, mas como o mecanismo pelo qual indivíduos constituem-se sujeitos, pois é no seio de uma ideologia que o indivíduo torna-se sujeito, não existindo ideologia sem sujeitos, nem sujeitos sem ideologia. Dessa forma, compreenda-se assujeitamento como "tornado sujeito por", devir da relação ideologia/indivíduo.

Por conseguinte, um indivíduo torna-se sujeito na e pela história, tendo em vista que esta é um imenso sistema natural-humano no interior do qual "[...] a Ideologia é eterna (omni-histórica) - enunciado esse que faz eco à expressão de Freud: 'o inconsciente é eterno”' (PÊCHEUX, 1997, p. 152). E é por meio dessa interface entre ideologia e inconsciente que o sujeito se constitui.

De acordo com o autor citado, ambos os predicamentos (ideologia e inconsciente) têm um mecanismo singular e comum, que diz respeito ao fato das estruturas-funcionamentos da ideologia e do inconsciente “[...] dissimular sua própria existência no interior do seu funcionamento, produzindo um tecido de

\footnotetext{
${ }^{6}$ Referimos-nos aqui às manifestações do inconsciente estruturado na linguagem sob formas de sonhos, atos falhos, chistes etc., que não se constituem objetos precípuos de análise da $\mathrm{AD}$, pois esta se preocupa com a instauração e os processos discursivos que se desenrolam sobre base material da língua, constituindo o discurso o objeto teórico de constituição dos sujeitos e dos sentidos.
} 
evidências 'subjetivas', devendo entender-se este último adjetivo não como 'que afetam o sujeito', mas 'nas quais se constitui o sujeito"' (PÊCHEUX, 1997, p. 152).

Assim, o sujeito se instaura enquanto tal, isto é, assujeita-se, interpelado pela ideologia, além de ser constituído pelo inconsciente. Dito de outra forma, é constituído pela ideologia e pelo inconsciente, por meio da interpelação e do assujeitamento, que sujeitos são construídos e instaurados. Tal concepção poderia até ser estruturada simbolicamente da seguinte maneira

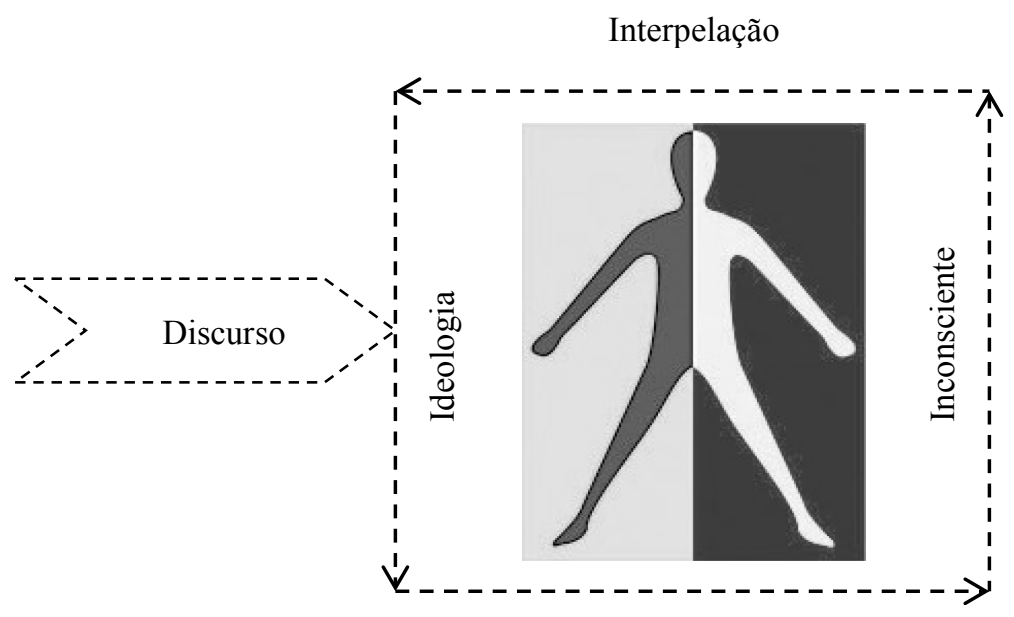

Assujeitamento

Um sujeito para ser sujeito é constituído pelo inconsciente, cuja estrutura-funcionamento dissimula sua existência no interior do seu próprio exercício funcional. É funcionando que o inconsciente produz evidências subjetivas para o sujeito, camuflando-lhe o fato de que o que ele é se dá pela sua inscrição em uma ideologia, que também lhe é algo constitutivo. Esse funcionamento do inconsciente e da ideologia é balizado pelos mecanismos da interpelação e do assujeitamento. $\mathrm{O}$ primeiro diz respeito ao fato do sujeito ser chamado a existência, representado por um teatro da consciência, em que a ideologia interpela indivíduos em sujeitos. O fato do "[...] (eu vejo, eu penso, eu falo, eu te vejo, eu te falo etc.) [vincula-se a] de onde se pode captar que se fala do sujeito, que se fala ao sujeito, antes de que o sujeito possa dizer 'Eu falo'”" (PÊCHEUX, 1997, p. 154); isto é, vincula-se ao lugar sócio-histórico ideologicamente marcado no qual se inscrevem os sujeitos. Já o assujeitamento, conforme mencionado anteriormente, refere-se ao devir dessa relação indivíduo/ideologia, é o tornar-se sujeito, inscrevendo-se nesses lugares.

Sendo, então, esse sujeito clivado tanto pela ideologia quanto pelo inconsciente, concebido dessemelhantemente do sujeito das outras vertentes linguísticas apresentadas na discussão que empreendemos mais acima, é o sujeito construído no mundo histórico da produção de conhecimentos. Um sujeito descentrado, cindido, interpelado pelas condições de produção discursiva, dinâmico e interativo, constituído na interação social, situando seus dizeres em relação aos dizeres do outro. Esse outro envolve tanto o interlocutor da mensagem (nível em que se projeta, ajusta-se a fala em relação ao sujeito ouvinte, ou seja, o nível intradiscursivo) como também a relação com outros discursos já existentes e constituídos historicamente, que permeiam a fala do sujeito enunciador, ou seja, o nível interdiscursivo.

Por isso que se refuta, no campo da discursividade, a concepção de sujeito uno, central e origem dos sentidos, porque, nos enunciados de um sujeito, outras vozes, outros discursos irrompem. De fato, o que se observa, conforme Pêcheux (1997), é uma ilusão do sujeito falante que se vê como a fonte, a origem do seu discurso (esquecimento $n^{o}$. 1) e como o mestre e dominador do seu dizer (esquecimento $n^{o}$. 2), ilusões essas que são estruturantes, pois são incisivas para a existência de sentidos e sujeitos e necessárias para que a linguagem funcione nas produções sentidurais e nos sujeitos.

De acordo com o autor, o 
[… esquecimento $n^{o} .1$ dá conta do fato de que o sujeito-falante não pode, por definição, se encontrar no exterior da formação discursiva que o domina. Nesse sentido, o esquecimento $n^{o}$. 1 remetia, por uma analogia com o recalque inconsciente, a esse exterior, na medida em que [...] esse exterior determina a formação discursiva em questão [e] o esquecimento $\mathrm{n}^{\circ} .2$ cobre exatamente o funcionamento do sujeito do discurso na formação discursiva que o domina, e que é aí, precisamente, que se apóia sua "liberdade" de sujeitofalante. (PECHEUX, 1997, p. 175, grifos do autor).

Cabe então reforçar e ratificar que é no imo da dúplice atividade constitutiva da ideologia e do inconsciente que sujeitos e sentidos são produzidos, pois é no seio de uma ideologia que indivíduos instauram-se sujeitos, é do e no interior de uma ideologia, dissimulada pelo funcionamento do inconsciente, que indivíduos tornam-se sujeitos a partir de uma inscrição discursiva. Uma pessoa torna-se um sujeito inconscientemente ao se posicionar, ao realizar uma tomada de posição, porque, ao se inscrever em um lugar discursivo, imediatamente o faz circunscrito em uma ideologia, nessa relação imaginária dos indivíduos com suas condições reais de existência, conforme concebeu Althusser (2003), endossado por Pêcheux (1997). Entretanto, a ideologia não é uma representação imaginária do mundo, invertida, deformada e de que basta interpretar tal inversão e deformação para resgatar o seu conteúdo verdadeiro, como comumente se entende. Para Althusser (2003), o objeto da ideologia é a relação do sujeito com o mundo ou, mais precisamente, com suas condições reais de existência. O autor defende que o indivíduo é produto das relações sociais, e que a ideologia é dada a ele nessas relações, ao que Pêcheux acrescenta dizendo que o ideológico, enquanto "representação" imaginária, está subordinado às forças materiais "que dirigem os homens", reinscrevendo-se nelas (PÊCHEUX, 1997, p. 146).

Uma das teses de Althusser é a de que a “[...] ideologia tem uma existência material.” (ALTHUSSER, 2003, p. 41). Sua tese aponta para a existência não espiritual, mas material das "ideias" ou de outras "representações". As "ideias" de um sujeito existem em seus atos, ou devem existir neles, inscritos em práticas, e essas práticas se inscrevem no seio da existência material de um aparelho ideológico. Em outros termos,

[...] a ideologia não é um ato de pensamento solitário do "indivíduo”, mas uma relação social que tem por objeto representações; e, além disso, que o objeto da representação não é a materialidade dos homens e da natureza, mas sim as relações sociais "reais", isto é, as relações práticas que põem em relação os homens entre si e com a natureza. (ALTHUSSER, 2003, p. 41).

Essa ideologia é material no sentido de que suas ideias são seus atos materiais inseridos em práticas materiais, que são reguladas por rituais materiais, definidos pelo aparelho ideológico pertinente às ideias desse sujeito. A partir disso, Althusser define que "[...] não existe prática senão através de e sob uma ideologia" e “[...] não existe ideologia senão através do sujeito e para sujeitos" (ALTHUSSER, 2003, p. 42).

Ainda segundo o autor (2003, p. 42), “A ideologia interpela os indivíduos como sujeitos.”. Ela existe para sujeitos, o que só é possível por meio da categoria sujeito e do modo de funcionamento dessa categoria, pois a ideologia tem por função, e é isso que a define, constituir indivíduos concretos enquanto sujeitos.

Destarte, ele propõe duas teses: “[...] só há prática através de e sob uma ideologia” e "[ [...] só há ideologia pelo sujeito e para o sujeito” (ALTHUSSER, 2003, p. 93).

Pêcheux, em conjunto a Haroche e Henry, complementa essa discussão althusseriana sobre o fato de o indivíduo ser interpelado pela ideologia dizendo que o funcionamento da ideologia em geral, como interpelação dos indivíduos em sujeitos, realiza-se por meio das formações ideológicas, que se caracterizam como "[...] um elemento suscetível de intervir - como uma força confrontada a outras forças - na conjuntura ideológica de uma formação social em um momento dado" (HAROCHE; PÊCHEUX; HENRY, 2007, p. 26). Sendo assim, "[ [...] cada formação ideológica constitui [...] um complexo de atitudes e de representações que não são nem 'individuais' e nem 'universais', mas que se relacionam mais ou menos diretamente a posições de classes em conflito umas em relação às outras." (HAROCHE; PÊCHEUX; HENRY, 2007, p. 26, grifos dos autores), fornecendo "a cada sujeito" sua "realidade", enquanto sistema de evidências e de significações percebidas-aceitas-experimentadas.

Dessa forma, a ideologia aparece enquanto relação imaginária transformada em práticas, reproduzindo as relações de produção vigentes em uma relação social, que tem por objeto representações que não dizem respeito à materialidade dos homens e da natureza, mas às relações sociais "reais". Ou seja, a ideologia, 
enquanto relações práticas que põem em relação os homens entre si e com a natureza, tem por escopo transformar indivíduos em sujeitos por meio dessas práticas e, por isso, “[ [...] só há prática através de e sob uma ideologia" e que "[...] só há ideologia pelo sujeito e para sujeitos" (PÊECHEUX, 1997, p. 149).

Existindo por meios de práticas, não é no campo das ideias que as ideologias existem e, portanto, não é aí que se encontra a possibilidade de entrever seu funcionamento. As ideologias têm existência material, e é nesse domínio que devem ser estudadas, não enquanto ideias. Deve-se, então, estudar as ideologias como conjunto de práticas materiais necessárias à reprodução das relações de produção, conforme Althusser (2003) aventou.

Nesse sentido, é nas práticas discursivas que se deve buscar o lugar de materialização das ideologias. É o discurso o lugar da materialização da ideologia, ao que Pêcheux faz um adendo, colocando que é a língua o lugar da materialização do discurso.

Desse modo, é a partir da materialidade linguística, instaurando o discurso, que se torna possível analisar e entrever o funcionamento da ideologia em concomitância ao inconsciente, pois, conforme já dito anteriormente, é no dúplice funcionamento dessas duas instâncias que sujeitos são construídos. É por meio delas que se produz um tecido de evidências subjetivas, nas quais indivíduos fazem-se sujeitos, e é a partir da noção de inconsciente que se concebe o sujeito, pois sua consciência está descentrada pelo inconsciente que camufla ao sujeito o fato de não agir sob sua intencionalidade, mas pelo viés de uma ideologia e circunscrição discursiva.

Por essa razão, Pêcheux (1997) estabeleceu os dois esquecimentos que constituem ilusões estruturantes para a existência tanto dos sujeitos como também dos sentidos, e necessárias para que a linguagem funcione enquanto lugar de práticas discursivas produtoras desses sujeitos e sentidos.

Considerando então que esses mecanismos de funcionamento do discurso repousam em formações imaginárias, não são os sujeitos físicos ou os seus lugares sócio-espaciais, nos quais esses sujeitos estão inscritos, que poderiam ser descritos no funcionamento discursivo, mas são as imagens resultantes de suas projeções (as formações imaginárias) que permitem a passagem de situações empíricas para as posições ocupadas pelos sujeitos no discurso.

Dessa maneira, o sujeito é sempre um sujeito histórico, entendido a partir dos influxos da exterioridade. Está sempre vinculado ao ideológico, ao histórico e ao social, atravessado pelo funcionamento de uma consciência descentrada pelo inconsciente e pelas condições ideológicas de sua existência enquanto sujeito.

\section{4 À GUISA DE UMA (IN)CONCLUSÃo}

Sendo assim, após esse célere percurso pela construção da noção de sujeito no campo teórico de algumas vertentes da ciência humana que se ocupa dos fatos de linguagem - a Linguística - , pudemos analisar as vias epistemológicas do entendimento do que é sujeito frente à linguagem. Ainda que perdure uma visão mecanicista da relação sujeito-outro-mundo-linguagem no campo de saber dos estudos linguísticos, ressaltada nas quatro estirpes teóricas recortadas para esta discussão, existem vertentes, como a $\mathrm{AD}$, que primam pela dispersão, pelo descentramento, desvelando a dinâmica das práticas linguageiras. Há, desse modo, uma consideração de aspectos da exterioridade, seja da ordem ideológica, psicanalista, história, filosófica, social, cultural, como da própria imanência linguística.

O sujeito, portanto, mesmo destituído de uma plena autonomia e de um lugar centro-motriz, não se amarra nas vias herméticas de uma estrutura positivista; ou se fecha num legado genético-biológico; ou se prende aos limites pragmáticos de uma situação de uso da língua; ou se assenta em um ponto monárquico de soberania, de administração dos poderes da significação em uma situação enunciativa.

Com efeito, é o sujeito em constante devir, em constante (des)construção mediante processos (des)identificatórios do intricamento discursivo das práticas de linguagem. Um sujeito que, na sua singularidade, refrata e reflete uma pluralidade de posicionamentos socioideológicos. Um sujeito que, na sua dispersão, constrói sua unidade pelas tomadas de posição e circunscrição a formações sociais (sua inscrição em extratos divisores da sociedade), reguladas por formações discursivas (regras de formação do que pode e 
deve ser dito em determinados lugares discursivos), intervindas por formações ideológicas (uma conjuntura de caráteres e de representações nem idiossincráticas e nem universais, mas construídas no meio sóciohistórico que permite a cada sujeito instituir sua "realidade", enquanto sistema de evidências e de significações percebidas-aceitas-experimentadas) e atravessadas por um complexo dominante, construído, alhures, por discursos outros anteriores, exteriores e posteriores ao fio do intradiscurso.

Por fim, é o sujeito do mundo histórico, constituído além dos limites da língua, em uma relação de alteridade, no crivo de um processo constante de interpelação, entre o eu-outro-mundo-linguagem, construindo efeitos de sentidos e de (des)construção de (contra)identificações que instauram indivíduos em sujeitos.

\section{REFERÊNCIAS}

ALTHUSSER, Louis. Aparelhos ideológicos de Estado: nota sobre os aparelhos ideológicos de Estado. 9. ed. Trad. Walter José Evangelista e Maria Laura Viveiros de Castro. Rio de Janeiro: Edições Graal, 2003.

BENVEnISTE, Émile. Problemas de lingüistica geral II. Trad. Eduardo Guimarães. São Paulo: Pontes, 1989. CHOMSKY, Noam. Sobre natureza e linguagem. Trad. Marylene Pinto Michael. São Paulo: Martins Fontes, 2006.

DOMINGUES, Ivan. O grau zero do conhecimento: o problema da fundamentação das ciências humanas. 2. ed. São Paulo: Edições Loyola, 1999.

HAROCHE, Claudine; PÊCHEUX, Michel; HENRY, Paul. A semântica e o corte saussuriano: língua, linguagem, discurso. Trad. Roberto Leiser Baronas e Fábio César Montanheiro In: BARONAS, Roberto Leiser (Org.). Análise do Discurso: apontamentos para uma história da noção-conceito de formação discursiva. São Carlos: Pedro \& João Editores, 2007.

NEVES, Maria Helena de Moura. A gramática funcional. São Paulo: Martins Fontes, 2004.

ORLANDI, Eni Pulcinelli. Interpretação: autoria, leitura e efeitos do trabalho simbólico. Petrópolis: Vozes, 1996.

PÊCHEUX, Michel. Semântica e discurso: uma crítica à afirmação do óbvio. 3 ed. Trad. Eni Pulcinelli Orlandi et al. Campinas: Editora da UNICAMP, 1997.

SAUSSURE, Ferdinand. Curso de Linguística Geral. 27. ed. Trad. A. Chelini et al. São Paulo: Cultrix, 2006.

Recebido em 19/04/12. Aprovado em 23/05/12. 